\title{
НОРМИРОВАНИЕ ПРОИЗВОДСТВЕННЫХ СТОЧНЫХ ВОД, ОТВОДИМЫХ В ЦЕНТРАЛИЗОВАННУЮ СИСТЕМУ ВОДООТВЕДЕНИЯ НАСЕЛЕННЫХ ПУНКТОВ РЕСПУБЛИКИ БЕЛАРУСЬ
}

\author{
Ю. В. Голод', С. А. Дубенок ${ }^{2}$ \\ 1 Научный сотрудник отдела нормирования воздействия на окружающую среду РуП «Центральный
научно-исследовательский институт комплексного использования водных ресурсов», Минск, Беларусь, e-mail: ylia-gold@таil.ru \\ ${ }^{2}$ К. т. н., заместитель директора по научной работе РУП «Центральный научно-исследовательский \\ институт комплексного использования водных ресурсов», Минск, Беларусь, e-mail: dsnega@list.ru
}

\begin{abstract}
Рефрерат
Нормирование производственных сточных вод при отведении в централизованные системы водоотведения (канализации) населенных пунктов является одним из стратегических направлений в области охраны окружающей среды. Большинство предприятий осуществляют отведение производственных сточных вод в централизованную систему водоотведения без предварительной очистки, что нарушает работу очистных сооружений сточных вод населенных пунктов, снижает эффективность очистки сточных вод и приводит к сбросу недостаточно очищенных сточных вод в водные объекты.

Установление прямых норм в виде отраслевых допустимых концентраций загрязняющих веществ в производственных сточных водах при их отведении в централизованные системы водоотведения не всегда возможно, что потребовало разработку методики, позволяющей проводить расчеты поступления загрязняющих веществ в составе производственных сточных вод в централизованные системы водоотведения.
\end{abstract}

Ключевые слова: сточные воды, очистные сооружения, системы водоотведения, нормирование.

\section{REGULATION OF INDUSTRIAL WASTEWATER DISCHARGED TO THE CENTRALIZED WATER DISPOSAL SYSTEM OF SETTLEMENTS OF THE REPUBLIC OF BELARUS}

\section{Abstract}

Rationing of industrial wastewater when discharging into a centralized sewerage system of settlements is one of the strategic directions in the field of environmental protection. Most enterprises discharge industrial wastewater into a centralized wastewater system without preliminary treatment, which disrupts the operation of wastewater treatment plants and reduces the efficiency of wastewater treatment and leads to the discharge of insufficiently treated wastewater into water bodies.

The establishment of direct norms in the form of sectoral permissible concentrations of pollutants in industrial wastewater when they are discharged into centralized sewerage systems is not always possible, which required the development of a methodology that makes it possible to calculate the intake of pollutants as part of industrial wastewater into centralized sewerage systems.

Keywords: waste water, purification plant, sewerage systems, rationing.

\section{Введение}

Проблемы нормирования отведения производственных сточных вод в централизованные системы водоотведения (канализации) предприятий водопроводно-канализационного хозяйства (далее ВКХ) являются актуальными для Республики Беларусь, так как до настоящего времени отсутствует законодательно закрепленная методика, в соответствии с которой можно проводить нормирование поступления производственных сточных вод в централизованную систему канализации.

Вопросы нормирования отведения сточных вод в централизованную систему водоотведения в Республике Беларусь регламентированы Водным кодексом Республики Беларусь [1], постановлением Совета Министров Республики Беларусь от 04.09.2019 № 594 «Правила технической эксплуатации систем питьевого водоснабжения и водоотведения (канализации) населенных пунктов» [2] и постановлением Совета Министров Республики Беларусь от 30.09.2016 № 788 «Привила пользования централизованными системами водоснабжения, водоотведения (канализации) в населенных пунктах» [3].

В настоящее время в Республике Беларусь нормирование сточных вод, отводимых предприятиями в централизованные системь канализации, осуществляется с использованием положений, изложенных в Правилах приема производственных сточных вод в системы канализации населенных пунктов, разработанных НИИ коммунального водоснабжения и очистки воды АКХ им. К. Д. Памфилова в 1984 г. (далее - методика Памфилова) [4]. Однако, как показывает практика, в настоящее время методика Памфилова имеет ряд существенных ограничений при проведении расчетов по установлению допустимых концентраций при отведении производственных сточных вод в централизованные системы водоотведения и далее на очистные сооружения сточных вод населенных пунктов.

\section{Методическая часть}

Развитие строительства канализационных сетей в Западной Европе и США приходится на вторую половину XIX - XX века.
Начало эксплуатации централизованной системы канализации в г. Минске приходится на 1930 г., до этого периода централизованная городская канализация в Минске отсутствовала. Удаление сточных вод осуществлялось из выгребных ям посредством ассенизации ассенизационным обозом. Учитывая отсутствие очистных сооружений, неочищенные сточные воды сбрасывались на рельеф местности или напрямую в водные объекты, что приводило к неблагоприятному эпидемиологическому состоянию населенного пункта. Несколько ранее, в 1894 г., началось строительство городской канализации в г. Москве, где до этого отведение сточных вод осуществлялось на поля фильтрации.

В этот же период появились первые требования к отведению сточных вод в сети к коммунальной канализации: воспрещалось отводить в городскую канализацию «всякие жидкости и воды конденсационные и из холодильников, грунтовые воды, атмоссрерные осадки (дождевые и снеговые воды), а также жидкости и воды, содержащие свыше 5 \% кислот или щелочей или имеющие температуpy свыше $40{ }^{\circ} \mathrm{C} »[5]$.

Начало строительства и запуска в эксплуатацию очистных сооружений биологической очистки в искусственных условиях приходится на 50-60-е годы XX века, в связи с чем в этот период появляются первые особые требования к отведению производственных сточных вод в сети городской канализации с дальнейшим отведением их на коммунальные очистные сооружения, так как производственные сточные воды, оказывают негативное воздействие на очистные сооружения биологической очистки в искусственных условиях.

К первому комплексному нормативному правовому акту в данной области можно отнести «Правила пользования коммунальными водопроводом и канализацией», утвержденные приказом МКХ РСФСР от 09.08.1960 № 243 [6]. Правила регламентировали, в том числе, «Особые условия при канализовании промышленных, коммунальных и других предприятий», в соответствии с которыми предприятие ВКХ определяло возможность подключения промпредприятий к коммунальной канализации на основании данных о количественных 
и качественных характеристиках отводимых производственных сточных вод, однако ограничения по качественным и количественным характеристикам не регламентированы.

Указанный документ определял общие условия, при которых осуществлялось присоединение промышленных предприятий к коммунальной канализации:

- наличие городских очистных сооружений, которые могут обеспечить надлежащую очистку промышленных сточных вод;

- наличие на предприятии предварительной очистки сточных вод перед выпуском их в централизованную систему канализации.

Документ также впервые ввел требования по порядку пользования канализацией в домовладениях и предприятиях, регламентировав общие требования к хозяйственно-бытовым сточным водам [5].

Одновременно с техническим требованиями разрабатываются и санитарно-эпидемиологические требования, ограничивающие отведение сточных вод, которые могут содержать опасные бактериальные загрязнения (бактерии сибирской язвы, сапа и др.) без предварительного обеззараживания - «Санитарные правила устройства и эксплуатации хозяйственно-фрекальной канализации» [7]. Санитарные правила распространялись на объекты нового строительства, реконструкцию и эксплуатацию внутренних и наружных сетей хозяйственнобытовой канализации жилых и общественных зданий, производственных и вспомогательных зданий промпредприятий, а также сооружений для очистки хозяйственно-бытовых сточных вод густонаселенных мест, промышленных предприятий и отдельно стоящих зданий [7].

В литературных источниках первые обобщенные требования к отведению производственных сточных вод в городскую канализацию населенных пунктов представлены Н. Ф. Федоровым и С. М. Шифриньм в издании «Канализация» 1968 г. [8].

Авторами издания методически обоснованы и дополнены требования действующих НПА [6, 7], уточнены диапазоны содержания отдельных загрязняющих веществ при их отведении в сети коммунальной канализации, так, например: «Смесь бытовых и производственных сточных вод при поступлении на очистные сооружения не должна иметь $\mathrm{pH}$ менее 6,5 и более 8,5» [8]. В издании также впервые встречается понятие «городские сточные воды» и излагаются требования к отведению сточных вод в дождевую канализацию, в части ограничения отведения производственных сточных вод (по согласованию с местными органам санитарного надзора только условно чистые производственные воды могут отводиться в сети дождевой канализации). Сформированы рекомендации к предварительной подготовке сточных вод к отведению в канализационные сети: обосновано применение раздельных сетей для промышленных сточных вод, применение регулирующих резервуаров для усреднения и выравнивания поступления промышленных сточных вод в коммунальную канализацию [8].

В публикации 1975 г. «Каналиазация: учебник для вузов» [9] затрагиваются вопросы эксплуатации сетей дождевой канализации, а также расширяются и уточняются общие и отдельные требования к отведению производственных сточных вод по конкретным отраслям промышленности: «сточные воды мелких предприятий, а также местной и пищевой промышленности по переработке сельскохозяйственных продуктов (например, картофелекрахмальной, молочной, пивоваренной и др.) могут приниматься в городские канализации без ограничения и в ряде случаев без предварительной обработки. Сточные воды некоторых предприятий, например, мясокомбинатов и кожевенных заводов, могут быть приняты в городские канализации только после их предварительной обработки и обеззараживания в целях предохранения от попадания патогенных бактерий.» [9]. Расширяется диапазон рН сточных вод до 9 ед. $\mathrm{pH}$ и устанавливается ограничение по содержанию взвешенных веществ в составе сбрасываемых сточных вод - не более $500 \mathrm{mг} / л$.

В 1976 г. утверждаются «Правила пользования коммунальными водопроводами и канализацией» [10] с отменой «Правил пользования коммунальными водопроводом и канализацией» 1960 г [6]. Новые правила дополняют предыдущий документ в части взаимоотношений предприятий ВКХ и предприятий-абонентов. Документ впервые вводит условия, на основании которых предприятия ВКХ имеют право ограничивать или исключать прием производственных сточных вод предприятий в сети канализации населенного пункта при несоответствии сточных вод определенным требованиям, что позволит предприятиям ВКХ упорядочить процесс очистки сточныХ вод на коммунальных очистных сооружениях.

Б. О. Ботук в издании «Канализационные сети» 1977 г. [11] также приводит требования к производственным сточным водам, сбрасываемым в сети канализации: «В канализацию могут быть сброшены бытовые и производственные сточные воды, а также воды от атмосферных осадков. В отношении сброса бытовых сточных вод никаких ограничений нет; в отношении производственных сточных вод имеются ограничения, направленные на защиту канализационных сооружений от коррозии, заиливания, образования взрывоопасных газов, возможного нарушения биологической очистки сточных вод и загрязнения водоемов токсическими веществами» [11].

Таким образом, научные публикации и законодательство периода 1960-1970 гг. устанавливали отдельные требования и ограничения по поступлению производственных сточных вод в сети городской коммунальной канализации и назрела необходимость закрепления этих требований на законодательном уровне в части проектирования, строительства и эксплуатации коммунальных сетей водоотведения и очистных сооружений на них.

В 1976 г. приказом Министерством жилищно-коммунального хозяйства РСФСР утверждена «Инструкция по приему промышленных сточных вод в городскую канализацию» [12], на основании которой разработаны и утверждены решением исполкома Моссовета № 127 от 20.01.1984 на срок до 3 лет «Правила приема производственных сточных вод в Московскую городскую канализацию (временные)».

Временные правила по сути явились обобщением основных требований, упомянутых в НПА и литературных источниках, к производственным сточным водам с применением для конкретного населенного пункта. Основным новшеством документа стало введение понятия «максимальные допустимые значения», которые в производственных сточных водах предлагалось определять с учетом:

- условий сброса сточных вод после коммунальных очистных сооружений в водный объект;

- установленных предельно допустимых концентраций загрязняющих веществ в воде водных объектов;

- возможности суммарного воздействия вредных веществ с одинаковыми лимитирующими признаками вредности;

- возможности задержания загрязняющих веществ городскими очистными сооружениями;

- соотношения объемов хозяйственно-бытовых и производственных сточных вод, поступающих на городские очистные сооружения с содержанием аналогичных загрязнений;

- возможности использования осадка сточных вод в качестве удобрений.

Опыт применения инструкции [12] позволил к 1984 г. большим межведомственным коллективом (трест Росводоканалналадка, Гипрокоммунводоканал, МосводоканалНИИпроект, УВКХ Москвы и Ленинграда) во главе с НИИ КВОВ АКХ им. К. Д. Памфилова разработать алгоритм и примеры расчета допустимых концентраций загрязняющих веществ в производственных сточных водах и изложить материал в составе «Правил приема производственных сточных вод в системы канализации населенньхх пунктов (методика Памфилова)» [4].

Методика Памфилова устанавливает порядок разработки местных «Правил приема производственных сточных вод в систему канализации» с расчетом допустимых концентраций загрязняющих веществ в производственных сточных водах и требованиями к их качеству с учетом конкретных условий. Правила приема разрабатываются на основании паспортизации водного хозяйства промышленных предприятий, сбрасывающих производственные сточные воды в канализационную сеть населенного пункта. Исходя из установленных в Правилах приема допустимых концентраций загрязняющих веществ и выданного органами по регулированию использования и охране вод системы Минводхоза СССР разрешения на спецводопользование или обязательного предписания по этому вопросу, предприятие ВКХ выдает промышленным предприятиям разрешения на сброс производственных сточных вод и заключает с ними договоры на отпуск воды и прием производственных сточных вод в коммунальную канализацию.

Правила приема содержат требования к количеству и составу производственных сточных вод, которые могут быть сброшены промпредприятиями в системы канализации населенных пунктов для совместного отведения и очистки со сточными водами населенных пунктов, а также нормы допустимых концентраций загрязняющих веществ, содержащихся в производственных сточных водах.

Научные издания этого периода также уточняют отдельные требования в части условий приема производственных сточных вод в сети коммунальной и дождевой канализации, в части ограничения требований к предварительной очистке сточных вод с указанием 
Вестник Брестского государственного технического университета. 2021

отдельных отраслей, а также в части ограничения максимальной концентрации загрязняющих веществ в составе сточных вод.

После распада Советского Союза большинство стран постсоветсвого пространства до начала 2000-х осуществляли прием производственных сточных вод в сети коммунальной канализации в соответствии с требованиями, изложенными в методике Памфилова [4].

Одни из первых стран, которые начали рассматривать и перерабатывать законодательно в сфере нормирования сточных вод, отводимых в сети городской канализации, являются Литва, Польша и Россия. К настоящему времени законодательство этих стран в области коммунального водоотведения претерпело наиболее значительные изменения, в то время как в других исследуемых странах рассмотрение данного вопроса осуществлялось значительно позже.

Российская Федерация. В настоящее время условия приема производственных сточных вод в централизованную систему водоотведения населенных пунктов России регламентированы «Правилами холодного водоснабжения и водоотведения» [13].

Правилами регламентируются и устанавливаются:

- общие требования к производственным сточным водам, отводимым промышленными предприятиями в централизованную систему водоотведения;

- максимальные допустимые значения показателей и (или) концентраций в натуральной пробе сточных вод (производственных сточных вод);

- максимальные допустимые значения показателей и (или) концентраций в натуральной пробе сточных вод (поверхностных сточных вод);

- требования к отбору проб и определению места отбора проб;

- эффективность удаления загрязняющих веществ на сооружениях биологической очистки;

- порядок определения размера и порядка компенсации расходов организации водопроводно-канализационного хозяйства при сбросе абонентами сточных вод, оказывающих негативное воздействие на работу централизованной системы водоотведения (расчет денежного возмещения убытков);

- перечень производственных процессов, при осуществлении которых абоненты обязаны иметь локальные очистные сооружения и осуществлять сброс в централизованную систему водоотведения сточные воды, прошедших предварительную очистку. Республика Казахстан. В настоящее время условия приема производственных сточных вод в систему водоотведения населенных пунктов Казахстана регламентированы «Правилами приема сточных вод в системы водоотведения населенных пунктов» [14].

Правилами приема сточных вод регламентируются и устанавливаются:

- общие требования к производственным сточным водам, отводимым промышленными предприятиями в централизованную систему водоотведения;

- требования к отбору проб и определению места отбора проб;

- требования к организации локальных очистных сооружений (жироуловителей) для предприятий, предоставляющих услуги по общественному питанию;

- условия приема хозяйственно-бытовых и производственных вод ассенизационным транспортом на оборудованных сливных пунктах.

Республика Литва. В настоящее время условия приема производственных сточных вод в систему водоотведения населенных пунктов Литвы регламентированы приказом Министерства окружающей среды Республики Литва «Об утверждении регулирования обращения (обработки) со сточными водами» № D1-236 от 17.05.2006 [15].

Правилами приема сточных вод регламентируются и устанавливаются:

- общие требования к производственным сточным водам, отводимым промышленными предприятиями в централизованную систему водоотведения;

- максимальные допустимые концентрации загрязняющих веществ в составе производственных сточных вод, отводимых в сети коммунальной канализации;

- перечень опасных загрязняющих веществ и их максимальные допустимые концентрации в составе производственных сточных вод.

Республика Польша. В настоящее время условия приема производственных сточных вод в систему водоотведения населенных пунктов Польши регламентированы Уставом от 07.06.2001 «О коллективном водоснабжении и коллективной канализации» № 72 [16].
Правилами приема сточных вод регламентируются и устанавливаются

- общие требования к производственным сточным водам, отводимым промышленными предприятиями в централизованную систему водоотведения;

- максимальные допустимые концентрации загрязняющих веществ в составе производственных сточных вод, отводимых в сети коммунальной канализации;

- перечень опасных загрязняющих веществ и их максимальные допустимые концентрации в составе производственных сточных вод.

Украина. В настоящее время условия приема производственных сточных вод в систему водоотведения населенных пунктов Украины регламентированы «Правилами приема сточных вод в системы водоотведения и Порядком определения размера платы, взимаемой за сверхнормативные сбросы сточных вод в системы водоотведения» [17].

Правилами приема сточных вод регламентируются и устанавливаются:

- общие требования к производственным сточным водам, отводимым промышленными предприятиями в централизованную систему водоотведения;

- требования к сбросу очищенных сточных вод после городских очистных сооружений в водный объект;

- эффективность удаления загрязняющих веществ на сооружениях биологической очистки;

- требования к содержанию тяжелых металлов в осадках сточных вод, которые могут использоваться как органические удобрения;

- требования к отбору проб и определению места отбора проб;

- максимальные допустимые значения показателей в пробе сточных вод;

- меры воздействия в случае нарушения требований по сбросу сточных вод в системы водоотведения (расчет денежного возмещения убытков);

- расчет допустимых концентраций загрязняющих веществ в составе производственных сточных вод с учетом поступления хозяйственно-бытовых сточных вод в сети водоотведения;

- концентрации загрязняющих веществ в составе хозяйственнобытовых сточных вод;

- условия приема хозяйственно-бытовых и производственных сточных вод ассенизационным транспортом на оборудованных сливных пунктах.

Молдова. В настоящее время условия приема производственных сточных вод в систему водоотведения населенных пунктов Молдовы регламентированы «Положением о требованиях к сбору, очистке и сбросу сточных вод в канализационную систему и/или в приемник для городских и сельских населенных пунктов» [18].

Правилами приема сточных вод регламентируются и устанавливаются:

- общие требования к производственным сточным водам, отводимым промышленными предприятиями в централизованную систему водоотведения;

- требования к сбросу очищенных сточных вод после городских очистных сооружений в водный объект;

- требования к содержанию тяжелых металлов в осадках сточных вод, которые могут использоваться как органические удобрения;

- требования к отбору проб и определению места отбора проб;

- максимальные допустимые значения концентраций в пробе сточных вод;

- расчет допустимых концентраций загрязняющих веществ в составе производственных сточных вод с учетом поступления хозяйственно-бытовых сточных вод в сети водоотведения;

- концентрация загрязняющих веществ в составе хозяйственнобытовых сточных вод.

Республика Беларусь. В настоящее время условия приема производственных сточных вод в централизованную систему водоотведения (канализации) населенных пунктов Беларуси регламентированы «Правилами пользования централизованными системами водоснабжения, водоотведения (канализации) в населенных пунктах» [3].

Правилами приема сточных вод регламентируются и устанавливаются:

- общие требования к производственным сточным водам, отводимым предприятиями в централизованную систему водоотведения; _ требования к отбору проб и определению места отбора проб; 
- максимальные допустимые концентрации загрязняющих веществ в составе производственных сточных вод в разрезе основных видов экономической деятельности.

\section{Заключение}

Проведенный анализ развития научных исследований и формирования законодательства по отведению сточных вод в централизованные системы водоотведения (канализации) позволяет сделать вывод, что общие (укрупненные) ограничительные условия к отведению сточных вод в централизованные системы водоотведения (канализации) применялись еще при строительстве сетей городской канализации в 1894 г.

С развитием технологий очистки сточных вод и ведением в эксплуатацию биологических очистных сооружений в искусственных условиях, а также с учетом развития и увеличения количества промышленных предприятий, осуществляющих сброс производственных сточных вод в сети коммунальной канализации с последующим отведением на коммунальные очистные сооружения биологической очистки в искусственных условиях, возникла необходимость установления особых условий для приема производственных сточных вод в городскую канализацию. В 60-е годы XX века в литературных источниках и нормативных правовых актах формируются общие требования к отведению производственных сточных вод в сети городской канализации, однако требования к качественному составу производственных сточных вод по-прежнему отсутствуют.

В 1976 г. принимается первый нормативный правовой акт, установивший общие требования к приему производственных сточных вод в сети коммунальной канализации населенных пунктов на территории РСФСР, - «Инструкция по приему промышленных сточных вод в городскую канализацию» и в ее развитие - «Правила приема производственных сточных вод в Московскую городскую канализацию» (1984 г.), которые наравне с общими требованиями к отведению производственных сточных вод включали также максимальные допустимые значения концентраций загрязняющих веществ в составе производственных сточных вод при их сбросе в сети городской канализации.

В 1984 г. на основе опыта применения Привил приема разработан методический документ, в котором впервые приведены алгоритм и примеры расчета допустимых концентраций загрязняющих веществ в производственных сточных водах с учетом качества сточных вод сбрасываемых после городских очистных сооружений в водные объекты, производительности и эффрективности работы очистных сооружений, качества хозяйственно-бытовых сточных вод - методика Памфилова. В методике Памфилова впервые представлен перечень загрязняющих веществ в составе производственных сточных вод для 13 отраслей промышленности и перечень загрязняющих веществ, не удаляемых в процессе биологической очистки.

На основании анализа действующего законодательства по отведению сточных вод в централизованную систему водоотведения населенных пунктов в ряде стран Таможенного союза и ЕС можно сделать вывод, что в большинстве стран, включая и Республику Беларусь, закреплены общие требования и ограничения в части качественных характеристик производственных сточных вод, поступающих на очистные сооружения сточных вод населенных пунктов. Однако методические подходы к возможности расчета допустимых концентраций загрязняющих веществ с учетом качественных и количественных характеристик производственных сточных вод и с учетом фактической эффективности очистных сооружений сточных вод населенных пунктов в рассмотренных странах (кроме Украины и Молдовы) отсутствуют.

В сложившихся условиях нормирования производственных сточных вод, отводимых в централизованные системы водоотведения (канализации) Республики Беларусь, необходимо наличие методики, позволяющей проводить расчеты и обоснование условий приема производственных сточных вод в централизованные системы водоотведения (канализации), при условии, когда доведенная максимальная концентрация загрязняющих веществ в составе производственных сточных вод в соответствии с постановлением Совмина № 788 превышает допустимую нагрузку на очистные сооружения сточных вод населенных пунктов.

В рамках исследования сформирован перечень требований, которые должна регламентировать национальная методика нормирования производственных сточных вод при отведении в централизованные системы водоотведения (канализации):

- общие требования к сточным водам, сбрасываемым в централизованную систему водоотведения (канализации);

- требования к отведению поверхностных сточных вод;

- требования по приему и контролю качества сточных вод, поступающих на очистные сооружения посредствам ассенизационного транспорта;

- перечень загрязняющих веществ в составе сточных вод, отводимых в централизованную систему водоотведения (канализации) по видам сточных вод;

- перечень загрязняющих веществ, запрещенных к сбросу в централизованную систему водоотведения (канализации);

- требования по достигаемой эфффективности удаления загрязняющих веществ в процессе очистки на очистных сооружениях сточных вод населенных пунктов;

- перечень отраслей промышленности, производственные сточные воды которых необходимо подвергать обязательной локальной очистке перед их отведением в централизованные системы водоотведения (канализации);

- максимальные допустимые концентрации загрязняющих веществ в составе производственных сточных вод в разрезе видов экономической деятельности;

- максимальные допустимые концентрации загрязняющих веществ в составе поверхностных сточных вод, при их отведении отдельным выпуском в централизованные системы водоотведения (канализации) и далее на очистные сооружения сточных вод населенных пунктов;

- методику расчета допустимых концентраций загрязняющих веществ в составе производственных сточных вод.

\section{Список использованных источников}

1. Водный кодекс Республики Беларусь [Электронный ресурс] 30 июля 2014 г., № 149-3 : принят Палатой представителей 2 апреля 2014 г. : одобр. Советом Респ. 11 апреля 2014 г. : в ред. Закона Респ. Беларусь от 18.06.2019 г. // ЭТАЛОН. Законодательство Республики Беларусь / Нац. центр правовой информ. Респ. Беларусь. - Минск, 2020.

2. Об утверждении Правил технической эксплуатации систем питьевого водоснабжения и водоотведения (канализации) населенных пунктов [Электронный ресурс] : постановление Совета Министров Респ. Беларусь, 04 сен. 2019 г., № 594 // Правовая платформа «Бизнес-Инфо». - Режим доступа: http://bii.by/tx.dll? d=408755\&f. - Дата доступа: 25.09.2020.

3. Об утверждении Правил пользования централизованными системами водоснабжения, водоотведения (канализации) в населенных пунктах [Электронный ресурс] : постановление Совета Министров Респ. Беларусь, 30 сен. 2016 г., № 788 // Национальный правовой Интернет-портал Республики Беларусь. - Режим доступа: https://pravo.by/document/?guid=12551\&p0=C21600788\&p1=1. - Дата доступа: 28.09.2020.

4. Правила приема производственных сточных вод в системы канализации населенных пунктов [Электронный ресурс] : приказ Мин. ЖКХ РСФСР, 2 мар. 1984 г., № 107 // Электронный фонд правовой и нормативно-технической документации. - Режим доступа: http://rdocs3.cntd.ru/document/1200037398. - Дата доступа: 15.08.2020.

5. Васильев, А. А. История системы городского жилищно-коммунального хозяйства дореволюционной России / А. А. Васильев, И. Г. Малков, В. И. ЧиркОв. - Гомель : БелГУТ, 2014 - 102 с.

6. Правила пользования коммунальными водопроводом и канализацией [Электронный ресурс] : приказ МКХ РСФСР, 9 сен. 1960 г., № 243 // Справочная правовая система КонсультантПлюс. - Режим доступа: http://www.consultant.ru/cons/cgi/online.cgi?req=doc\&base=ESU\&n=18627\#09810238697899507. - Дата доступа: 10.08.2020.

7. Санитарные правила устройства и эксплуатации хозяйственнофекальной канализации [Электронный ресурс] : утв. заместителем Главного государственного санитарного врача СССР 6 дек. 1963 г. № 459-63 // Информационно-правовое обеспечение Гарант. - Режим доступа: https://base.garant.ru/70832860. - Дата доступа: 18.08.2020.

8. Федоров, Н. Ф. Канализация / Н. Ф. Федоров, С. М. Шифрин. Москва : Издательство «Высшая школа», 1968. - 592 с.

9. Яковлев, С. В. Канализация. Учебник для вузов. Изд. 5-е, перераб. и доп. / С. В. Яковлев [и др.]. - Москва: Стройиздат, 1975. - 632 с. 
Вестник Брестского государственного технического университета. 2021

10. Правила пользования коммунальными водопроводами и канализацией [Электронный ресурс]: приказ Министерства ЖКХ РСФСР, 19 март. 1976, № 155// Справочная правовая система КонсультантПлюс. - Режим доступа : http://www.consultant.ru/cons/cgi Ionline.cgi?req=doc\&base $=E S U \& n=18699 \# 07495854180683443$. Дата доступа: 10.08.2020.

11. Ботук, Б. О. Канализационные сети: учеб. пособие для вузов / Б. О. Ботук, Н. Ф. Федоров. - Изд. 2-е. перераб. и доп. - Москва : Стройиздат, 1977. - $256 \mathrm{c}$.

12. Инструкция по приему промышленных сточных вод в городскую канализацию [Электронный ресурс] : приказ Министерства ЖКХ РСФСР, 1 нояб. 1976 г., № 485 // Электронный фонд правовой и нормативно-технической документации. - Режим доступа: http://rdocs3.cntd.ru/document/1200037398. - Дата доступа: 15.08.2020.

13. Правил холодного водоснабжения и водоотведения и о внесении изменений в некоторые акты Правительства Российской Федерации [Электронный ресурс] : постановление Правительства РФ, 29 июл. 2013 г., № 644 // Электронный фонд правовой и нормативно-технической документации. - Режим доступа: http://docs.cntd.ru/document/499036854. - Дата доступа: 17.08.2020.

14. Правила приема сточных вод в системы водоотведения населенных пунктов [Электронный ресурс] : приказ Министра национальной экономики Республики Казахстан, 20 июл. 2015 г. № 546 // Информационная система «Параграфф. - Режим доступа: https://online.zakon.kz/Document/?doc_id=38950650\#pos=0;0. Дата доступа: 11.09.2020.

15. Об утверждении регулирования обращения (обработки) со сточными водами [Электронный ресурс] : приказ Министерства окружающей среды Республики Литва, 17 май 2006 г., № D1-236 // Lietuvos Respublikos Seimo kanceliarija. - Режим доступа: https://e-seimas.Irs.It/portal/legalAct/lt/TAD/TAIS.276576. - Дата доступа: 13.04 .2020$.

16. О коллективном водоснабжении и коллективной канализации [Электронный ресурс] : приказ канцелярии Сейма Республики Польша, 07 июн. 2001 г., № 72 // Правовая информационная система LexLege. - Режим доступа: https://www.lexlege.pl/ustawa-ozbiorowym-zaopatrzeniu-w-wode-i-zbiorowym-odprowadzaniusciekow/. Режим доступа: 15.04.2020.

17. Об утверждении Правил приема сточных вод в системы водоотведения и Порядка определения размера платы, взимаемой за сверхнормативные сбросы сточных вод в системы водоотведения [Электронный ресурс] : приказ Министерства регионального развития, строительства жилищно-коммунального управления Украины, 1 дек. 2017 г., № 316 // Информационная система Континент. - Режим доступа: http://continent-online.com/Document/?doc_id=36705649\#pos=0;0. - Дата доступа: 22.05.2020.

18. Об утверждении Положения о требованиях к сбору, очистке и сбросу сточных вод в канализационную систему и/или в приемник для городских и сельских населенных пунктов [Электронный ресурс] : постановление Правительства Респ. Молдова, 25 нояб. 2013 г. № 950 // База данных Законодательство стран СНГ. - Режим доступа: https://base.spinform.ru/show_doc.fwx?rgn=64899. - Дата доступа: 24.07.2020.

\section{References}

1. Vodnyj kodeks Respubliki Belarus' [Elektronnyj resurs] : 30 iyulya 2014 g., № 149-Z : prinyat Palatoj predstavitelej 2 aprelya 2014 g. : odobr. Sovetom Resp. 11 aprelya 2014 g. : v red. Zakona Resp. Belarus' ot 18.06 .2019 g. // ETALON. Zakonodatel'stvo Res-publiki Belarus' / Nac. centr pravovoj inform. Resp. Belarus'. - Minsk, 2020.

2. Ob utverzhdenii Pravil tekhnicheskoj ekspluatacii sistem pit'evogo vodosnabzheniya i vodootvedeniya (kanalizacii) naselennyh punktov [Elektronnyj resurs] : postanovlenie Soveta Ministrov Resp. Belarus', 04 sen. 2019 g., № 594 // Pravovaya platforma «Biznes-Info». Rezhim dostupa: http://bii.by/tx.dll?d=408755\&f. - Data dostupa: 25.09 .2020$.

3. Ob utverzhdenii Pravil pol'zovaniya centralizovannymi sistemami vodosnabzhe-niya, vodootvedeniya (kanalizacii) v naselennyh punktah [Elektronnyj resurs] : postanov-lenie Soveta Ministrov Resp. Belarus', 30 sen. 2016 g., № 788 // Nacional'nyj pravovoj Internetportal Respubliki Belarus'. - Rezhim dostupa: https://pravo.by/document/?guid=12551\&p0=C21600788\&p1=1. Data dostupa: 28.09.2020.
4. Pravila priema proizvodstvennyh stochnyh vod $\mathrm{v}$ sistemy kanalizacii naselennyh punktov [Elektronnyj resurs] : prikaz Min. ZHKKH RSFSR, 2 mar. 1984 g., № 107 // Elek-tronnyj fond pravovoj i normativnotekhnicheskoj dokumentacii. - Rezhim dostupa: http://rdocs3.cntd.ru/document1200037398. - Data dostupa: 15.08.2020

5. Vasil'ev, A. A. Istoriya sistemy gorodskogo zhilishchno-kommunal'nogo hozyajstva dorevolyucionnoj Rossii / A. A. Vasil'ev, I. G. Malkov, V. I. CHirkov. - Gomel' : BelGUT, 2014 - 102 s.

6. Pravila pol'zovaniya kommunal'nymi vodoprovodom i kanalizaciej [Elektronnyj resurs] : prikaz MKKH RSFSR, 9 sen. 1960 g., № 243 // Spravochnaya pravovaya sistema Kon-sul'tantPlyus. - Rezhim dostupa: http://www.consultant.ru/cons/cgi/online.cgi?req=doc\&base=ESU\& $n=186$ 27\#09810238697899507. - Data dostupa: 10.08.2020.

7. Sanitarnye pravila ustrojstva i ekspluatacii hozyajstvenno-fekal'noj kanaliza-cii [Elektronnyj resurs] : utv. zamestitelem Glavnogo gosudarstvennogo sanitarnogo vra-cha SSSR 6 dek. $1963 \mathrm{~g}$. № 459-63 // Informacionno-pravovoe obespechenie Garant. - Rezhim dostupa: https://base.garant.ru/70832860. - Data dostupa: 18.08.2020.

8. Fedorov, N. F. Kanalizaciya / N. F. Fedorov, S. M. SHifrin. - Moskva : Izdatel'-stvo «Vysshaya shkola», 1968. - $592 \mathrm{~s}$.

9. YAkovlev, S. V. Kanalizaciya. Uchebnik dlya vuzov. Izd. 5-e, pererab. i dop./ S. V. YAko-vlev [i dr.]. - Moskva: Strojizdat, 1975. - 632 s.

10. Pravila pol'zovaniya kommunal'nymi vodoprovodami i kanalizaciej [Elektronnyj resurs]: prikaz Ministerstva ZHKKH RSFSR, 19 mart 1976, № 155 // Spravochnaya pravo-vaya sistema Konsul'tantPlyus. - Rezhim dostupa : http://www.consultant.ru/cons/cgi /online.cgi?req=doc\&base $=$ ESU\&n=18699\#07495854180683443. Data dostupa: 10.08 .2020$.

11. Botuk, B. O. Kanalizacionnye seti: ucheb. posobie dlya vuzov / B. O. Botuk, N. F. Fedorov. - Izd. 2-e. pererab. i dop. - Moskva : Strojizdat, 1977. $-256 \mathrm{~s}$.

12. Instrukciya po priemu promyshlennyh stochnyh vod $v$ gorodskuyu kanalizaciyu [Elektronnyj resurs] : prikaz Ministerstva ZHKKH RSFSR, 1 noyab. 1976 g., № 485 // Elek-tronnyj fond pravovoj i normativno-tekhnicheskoj dokumentacii. - Rezhim dostupa: http://rdocs3.cntd.ru/document/1200037398. - Data dostupa: 15.08.2020.

13. Pravil holodnogo vodosnabzheniya i vodootvedeniya i o vneseni izmenenij v neko-torye akty Pravitel'stva Rossijskoj Federacii [Elektronnyj resurs] : postanovlenie Pravitel'stva RF, 29 iyul. 2013 g., № 644 // Elektronnyj fond pravovoj i normativno-tekhnicheskoj dokumentacii. - Rezhim dostupa: http://docs.cntd.ru/document/499036854. - Data dostupa: 17.08.2020.

14. Pravila priema stochnyh vod $v$ sistemy vodootvedeniya naselennyh punktov [Elek-tronnyj resurs] : prikaz Ministra nacional'noj ekonomik Respubliki Kazahstan, 20 iyul. 2015 g., № 546 // Informacionnaya sistema "Paragraf». - Rezhim dostupa: https://online.zakon.kz/Document/?doc id=38950650\#pos=0;0. - Data dostupa: 11.09.2020

15. Ob utverzhdenii regulirovaniya obrashcheniya (obrabotki) so stochnymi vodami [Elek-tronnyj resurs] : prikaz Ministerstva okruzhayushchej sredy Respubliki Litva, 17 maj 2006 g., № D1-236 // Lietuvos Respublikos Seimo kanceliarija. - Rezhim dostupa: https://eseimas.Irs.It/portal/legalAct/lt/TAD/TAIS.276576. - Data dostupa: 13.04.2020.

16. 0 kollektivnom vodosnabzhenii i kollektivnoj kanalizacii [Elektronny] resurs] : prikaz kancelyarii Sejma Respubliki Pol'sha, 07 iyun. $2001 \mathrm{~g}$., № 72 // Pravovaya informa-cionnaya sistema LexLege. Rezhim dostupa: https://www.lexlege.pl/ustawa-o-zbiorowym-zaopatrzeniu-w-wode-izbiorowym-odprowadzaniu-sciekow/. - Rezhim dostupa: 15.04.2020.

17. Ob utverzhdenii Pravil priema stochnyh vod v sistemy vodootvedeniya i Poryadka opredeleniya razmera platy, vzimaemoj za sverhnormativnye sbrosy stochnyh vod v siste-my vodootvedeniya [Elektronnyj resurs] : prikaz Ministerstva regional'nogo razvitiya, stroitel'stva zhilishchnokommunal'nogo upravleniya Ukrainy, 1 dek. 2017 g., № 316 // lnformacionnaya sistema Kontinent. - Rezhim dostupa: http://continentonline.com/Document/?doc_id=36705649\#pos=0;0. - Data dostupa: 22.05.2020.

18. Ob utverzhdenii Polozheniya o trebovaniyah $\mathrm{k}$ sboru, ochistke sbrosu stochnyh vod v kanalizacionnuyu sistemu i/lii v priemnik dlya gorodskih i sel'skih naselennyh punktov [Elektronnyj resurs] : postanovlenie Pravitel'stva Resp. Moldova, 25 noyab. 2013 g., № 950 // Baza dannyh Zakonodatel'stvo stran SNG. - Rezhim dostupa: https://base.spinform.ru/show_doc.fwx?rgn=64899. - Data dostupa: 24.07.2020

Материал поступил в редакцию 15.05.2021 